\title{
(2) OPEN ACCESS \\ Improving peripherally inserted central catheter appropriateness and reducing device-related complications: a quasiexperimental study in 52 Michigan hospitals
}

\author{
Vineet Chopra (D) , 1,2,3 Megan O'Malley, ${ }^{1,3}$ Jennifer Horowitz, ${ }^{1,3}$ \\ Qisu Zhang, ${ }^{1,3}$ Elizabeth McLaughlin, ${ }^{1,3}$ Sanjay Saint, ${ }^{1,2}$ \\ Steven J Bernstein, ${ }^{3}$ Scott Flanders ${ }^{1,3}$
}

- Additional material is published online only. To view please visit the journal online (http://dx.doi.org/10.1136/ bmjqs-2021-013015).

'Division of Hospital Medicine, Department of Internal Medicine, University of Michigan Health System, Ann Arbor, Michigan, USA

${ }^{2}$ Medicine Service, Lieutenant Colonel Charles S. Kettles Department of Veterans Affairs Medical Center, Ann Arbor, Michigan, USA

${ }^{3}$ Hospital Medicine Safety Consortium, University of Michigan Health System, Ann Arbor, MI, USA

\section{Correspondence to}

Dr Vineet Chopra, Department of Internal Medicine, University of Michigan Health System, Ann Arbor, USA; vineetc@umich.edu

Received 11 January 2021 Revised 3 March 2021 Accepted 13 March 2021

\section{Check for updates}

(c) Author(s) (or their employer(s)) 2021. Re-use permitted under CC BY-NC. No commercial re-use. See rights and permissions. Published by BMJ.

To cite: Chopra V,

O'Malley M, Horowitz J, et al. BMJ Qual Saf Epub ahead of print: [please include Day Month Year]. doi:10.1136/ bmjqs-2021-013015

\begin{abstract}
Background The Michigan Appropriateness Guide for Intravenous Catheters (MAGIC) provides evidence-based criteria for peripherally inserted central catheter (PICC) use. Whether implementing MAGIC improves PICC appropriateness and reduces complications is unknown. Methods A quasiexperimental study design to implement MAGIC in 52 Michigan hospitals was used. Data were collected from medical records by trained abstractors. Hospital performance on three appropriateness criteria was measured: short-term PICC use ( $\leq 5$ days), use of multilumen PICCs and PICC placement in patients with chronic kidney disease. PICC appropriateness and device complications preintervention (January 2013 to December 2016) versus postintervention (January 2017 to January 2020) were compared. Change-point analysis was used to evaluate the effect of the intervention on device appropriateness. Logistic regression and Poisson models were fit to assess the association between appropriateness and complications (composite of catheter occlusion, venous thromboembolism (VTE) and central line-associated bloodstream infection (CLABSI)).

Results Among 38592 PICCs, median catheter dwell ranged from 8 to 56 days. During the preintervention period, the mean frequency of appropriate PICC use was $31.9 \%$ and the mean frequency of complications was $14.7 \%$. Following the intervention, PICC appropriateness increased to $49.0 \%$ (absolute difference $17.1 \%$, $\mathrm{p}<0.001$ ) while complications decreased to $10.7 \%$ (absolute difference $4.0 \%, p=0.001$ ). Compared with patients with inappropriate PICC placement, appropriate PICC use was associated with a significantly lower odds of complications (OR $0.29,95 \% \mathrm{Cl} 0.25$ to 0.34 ), including decreases in occlusion (OR $0.25,95 \% \mathrm{Cl}$ 0.21 to 0.29$)$, CLABSI (OR $0.61,95 \% \mathrm{Cl} 0.46$ to 0.81 ) and VTE (OR $0.40,95 \% \mathrm{Cl} 0.33$ to 0.47 , all $\mathrm{p}<0.01)$. Patients with appropriate PICC placement had lower rate of complications than those with inappropriate PICC use (incidence rate ratio $0.987,95 \% \mathrm{Cl} 0.98$ to 0.99 , $\mathrm{p}<0.001)$.

Conclusions Implementation of MAGIC in Michigan hospitals was associated with improved PICC appropriateness and fewer complications. These findings
\end{abstract}

have important quality, safety and policy implications for hospitals, patients and payors.

\section{INTRODUCTION}

Because they can be inserted at the bedside, are safer to insert than other central venous catheters and facilitate transitions of care, peripherally inserted central catheters (PICCs) have become one of the most prevalent vascular access devices in US hospitals. ${ }^{12}$ Like other central venous catheters, however, PICCs are associated with infectious and non-infectious risks including venous thromboembolism (VTE) and central line-associated bloodstream infection (CLABSI). ${ }^{3-6}$ Additionally, PICC occlusion remains one of the most common device-complications and leads to delays in treatment, increase in cost and in some cases, PICC replacement. $^{78}$

One strategy to avoid PICC-related adverse events is to only place the device when it is appropriate: that is, when the benefits of use outweigh risks. The Michigan Appropriateness Guide for Intravenous Catheters (MAGIC) offers an evidence-based strategy to inform clinicians on when it is appropriate to place a PICC. ${ }^{9}$ Developed by a multidisciplinary panel, MAGIC provides appropriateness ratings for PICC use, taking into account duration of therapy, the type of infusion being delivered and the indication for treatment. Interventions using MAGIC have demonstrated more appropriate PICC use and a decrease in central line days and device utilisation. ${ }^{10}$ However, 
whether implementing MAGIC reduces device-related complications is not known. Improving PICC appropriateness while also reducing complications would make a compelling case for implementing MAGIC in hospitals.

In partnership with a statewide safety-focused collaborative, we designed a multimodal intervention to assess the impact of MAGIC on PICC appropriateness and device-associated complications.

\section{METHODS}

\section{Study, setting and design}

We used data from the Michigan Hospital Medicine Safety (HMS) Consortium from 1 January 2013 to 13 January 2020 to examine the association between PICC appropriateness and major PICCrelated complications (composite of CLABSI, VTE and catheter occlusion). A collaborative quality initiative funded by Blue Cross Blue Shield of Michigan and Blue Care Network, a core initiative of HMS is focused on measuring and improving PICC use and outcomes in participating hospitals. ${ }^{11}$ The design and setting of this project and the consortium have been previously described. ${ }^{12}{ }^{13}$ Beginning 1 January 2013, trained abstractors at each hospital collected data using a defined protocol, sampling frame and standardised template. Hospitalised medical patients who received PICCs while admitted to a general medical ward or intensive care unit (ICU) during clinical care were eligible for inclusion. Patients were excluded if they were under the age of 18 years, pregnant, admitted to a non-medicine service (eg, surgery) or in observation status. Every 14 days, each hospital collected detailed data on the first 17 eligible patients that received a PICC at their facility, with at least 7 PICCs placed in an ICU setting. All patients were prospectively followed until the PICC was removed, a major complication or death occurred or 30-day elapsed following insertion (whichever occurred first). Follow-up occurred via a combination of medical record review (eg, chart abstraction) and telephone calls at 7, 14 and 30 days. To ensure data quality and integrity, annual data audits were performed at each participating hospital by the HMS coordinating centre at the University of Michigan.

\section{Patient, provider and device data}

Patient characteristics (eg, demographics, comorbidities, medications, physical findings, imaging and laboratory results) were abstracted from hospital medical records. For patients with more than one PICC, the first PICC was included and subsequent devices were excluded $(n=2988)$. PICC characteristics, including indication for insertion, catheter gauge, number of lumens and insertion attempts, were abstracted from the physician order, the vascular access nurse insertion note or the radiology provider insertion note, as available. Provider characteristics, including the specialty of the attending physician and the operator that inserted the PICC were collected from medical records. In addition, data regarding consultation with specialists prior to PICC insertion (eg, nephrologists for PICC use in patients with chronic kidney disease (CKD)) were also recorded.

\section{Implementation strategy and intervention design}

To improve PICC appropriateness, we designed and implemented an evidence-based, pay-for-performance intervention based on MAGIC. We informed our intervention using theory-based guidance and used a Type 1 hybrid effectiveness implementation strategy, which focused on the effectiveness outcomes of an intervention, while exploring the implementability' of the same. ${ }^{14}$ The intervention was based on three targets aimed at corresponding appropriateness criteria: reducing short term PICC use ( $\leq 5$ days), decreasing use of multilumen devices and avoiding PICC placement in patients with CKD (defined as an estimated glomerular filtration rate $<45 \mathrm{~mL} / \mathrm{min} / 1.73$ $\mathrm{m}^{2}$ ), unless approved by a nephrologist prior to insertion. To reach these targets, hospitals were given access to a toolkit that consisted of: (a) an online learning platform; ${ }^{15}$ (b) access to subject matter experts; (c) knowledge sharing at quarterly in-person meetings and (d) feedback on performance via a central website. The toolkit included educational materials, summaries of best practices and peer-reviewed publications, electronic order-set templates, policies and protocols based on MAGIC, strategies to empower vascular access teams to make device decisions and tactics to engage subspecialists such as nephrologists and infectious diseases to approve PICC use in appropriate settings. The toolkit was introduced 1 January 2017 and is available online at: https://www.improvepicc.com/implementation.html. To complement the toolkit, quarterly in-person meetings where unblinded hospital performance data related to performance on appropriateness targets, examples of innovations and best practices across hospitals and challenges and solutions were featured. Participating sites received annual payments for their quality improvement efforts, with partial to full payment based on performance on each of the three criteria.

\section{Assessing PICC appropriateness and PICC-related complications}

We assessed PICC appropriateness at the hospital level, based on whether or not devices placed at the site met all three appropriateness criteria. Data from 52 hospitals were included in the analysis preintervention and postintervention; however, given changes within the collaborating hospitals throughout the study period with some hospitals dropping out of HMS and others joining the collaborative, hospital-level analysis was restricted to 41 hospitals that participated throughout the intervention. Within each hospital, 
appropriateness assessments were made on the patient level such that overall hospital performance was calculated and shared via the online platform. To control for competing risk, patients who died during the period of review were excluded from the analysis. Complications per PICC were measured at each hospital using standardised definitions and included catheter occlusion, VTE and CLABSI. ${ }^{13}$ Catheter occlusion was defined as documentation of failure to aspirate, flush the catheter and/or use of tissue plasminogen activator for catheter-related indications. ${ }^{8}$ VTE was defined as clinically suspected deep vein thrombosis (DVT) and/ or pulmonary embolism (PE) not present at the time of PICC placement subsequently confirmed via imaging (ultrasonography or venogram for DVT; CT, highprobability ventilation-perfusion scan or pulmonary angiogram for PE). CLABSI was defined in accordance with the CDC's National Healthcare Safety Network criteria or if 'CLABSI', 'line bactaeremia' or, 'line sepsis' were documented in the medical record. ${ }^{16}$ As with appropriateness, rates of complications were shared with hospitals via an online dashboard and quarterly in-person meetings. This report focuses on effectiveness outcomes; the assessment of implementation fidelity, barriers and facilitators is ongoing.

\section{Statistical analysis}

We performed two main analyses. First, to evaluate the effect of the intervention on PICC appropriateness and complications, we used change-point analysis and the associated cumulative sum (CUSUM) method as described by Taylor et al. ${ }^{1718}$ This approach uses a mean-shift model with CIs obtained through bootstrap analysis so as to provide robust estimation of outcomes in relation to intervention onset. This method was preferable to a Poisson or mixed effects logistic approach because our interest was to identify change points in relation to the intervention, rather than compare means across an a priori assigned time point. Second, to examine the association between appropriateness and complications (composite of occlusion, VTE and CLABSI), we fit multilevel mixed effects logistic regression (accounting for patients nested within hospitals) and mixed effects Poisson models (accounting for rate of events) adjusted for patient-level, device-level and facility-level covariates. Results were expressed as ORs and incidence rate ratios (IRRs) with corresponding 95\% CI.

All analyses were performed in Stata, V.16 (Stata, College Station, Texas, USA). A two-sided $\mathrm{p}<0.05$ was considered significant.

\section{RESULTS}

From 1 January 2013 to 13 January 2020, data from 41738 PICCs placed in 38592 unique patients in 52 hospitals were available for analysis. Across hospitals, a majority of patients that received PICCs were men $(51.3 \%)$, with a median age of 64 years and a median
Charlson comorbidity score of 3 . The top three indications for PICC insertion were intravenous antibiotics (51.9\%), difficult access/need for blood draws (20.3\%) and medications requiring central access (11.7\%); the indication for insertion was not documented for 3598 (9.3\%) PICCs. Among PICCs sampled, 10953 (28.4\%) were placed in ICU settings. Most PICCs were inserted by vascular access teams $(n=26644$ (69.0\%)), but some were placed by interventional radiologists $(n=7171(18.6 \%))$.

Compared with patients with appropriate PICC use, patients with inappropriate PICC use were younger (63.3 vs 64.5 years), more likely to be black (21.9\% vs $18.8 \%)$ and women $(52.5 \%$ vs $43.0 \%$, all $\mathrm{p}<0.001)$. With respect to category of appropriateness, $82.1 \%$ of PICCs were inappropriate because multilumen PICCs were inserted where a single lumen device would have been sufficient, 29.2\% were placed for $\leq 5$ days and 25.9\% were placed in patients with CKD (table 1).

\section{Preintervention appropriateness and frequency of complications}

In the preintervention period, most PICCs placed were double-lumen devices $(n=10156,46.0 \%)$, followed by single-lumen $(n=9354,42.4 \%)$ and triple-lumen catheters $(n=2571,11.6 \%)$. The median duration of PICC use across hospitals was 13.5 days (range: 8-56.5 days).

In the preintervention period, the baseline frequency of inappropriate PICC use (composite of $\leq 5$ days, multilumen use or PICC use in patients with CKD) was $68.1 \%$ (31.8\%-96.3\% across hospitals). The proportion of PICCs that were inappropriate varied as follows: dwell time $\leq 5$ days $20.9 \%$ (5.4\%-36.0\% across hospitals); multilumen catheters 57.6\% (7.1\%93.9\% across hospitals) and use in CKD $17.3 \%$ (0.2\%-28.9\% across hospitals).

The baseline frequency of complications was $14.7 \%$ (median 2.0\%-31.0\% across hospitals). The frequency of catheter occlusion was 10.6\% (0.5\%-27.0\% across hospitals), CLABSI 1.8\% (0.0\%-5.2\% across hospitals) and VTE 3.3\% (0.0\%-8.5\% across hospitals).

\section{Postintervention appropriateness and frequency of complications}

Following implementation, inappropriate PICC use decreased from $68.1 \%$ to $51.0 \%$ (absolute reduction $=17 \%, \mathrm{p}<0.001$; range of absolute decrease $17.3 \%-80.5 \%$ across hospitals). Overall, improvement in appropriateness ranged from $-5.2 \%$ (one hospital) to $+70.3 \%$ across 41 hospitals (figure 1 ). Use of multilumen devices improved the most, decreasing from $57.6 \%$ preintervention to $39.6 \%$ postintervention (absolute reduction $=18 \%, \mathrm{p}<0.001$; range of absolute decrease 3.8\%-74.4\% across hospitals). Similarly, for PICC dwell $\leq 5$ days, improvement from $20.9 \%$ preintervention to $13.6 \%$ postintervention was observed (absolute reduction $=7.3 \%, \mathrm{p}<0.001$; range 


\section{Original research}

Table 1 Demographic, clinical and device characteristics for all patients that received peripherally inserted central catheters (stratified by PICC appropriateness)

\begin{tabular}{|c|c|c|c|c|}
\hline & $\begin{array}{l}\text { Total } \\
(\mathrm{n}=38592)\end{array}$ & $\begin{array}{l}\text { Appropriate placement } \\
(\mathrm{n}=15128)\end{array}$ & $\begin{array}{l}\text { Inappropriate placement } \\
(\mathrm{n}=23464)\end{array}$ & $P$ value \\
\hline \multicolumn{5}{|l|}{ Demographics } \\
\hline Age, median (IQR) & $64(52.9-74.8)$ & $64.5(53.4-75.2)$ & $63.3(52.1-74.1)$ & $<0.001$ \\
\hline Women, n (\%) & $18809(48.7 \%)$ & $6501(43.0 \%)$ & $12308(52.5 \%)$ & $<0.001$ \\
\hline \multicolumn{5}{|l|}{ Race, n (\%) } \\
\hline White & $28540(74.0 \%)$ & $11466(75.8 \%)$ & $17074(72.8 \%)$ & $<0.001$ \\
\hline Black & $7975(20.7 \%)$ & $2838(18.8 \%)$ & $5137(21.9 \%)$ & $<0.001$ \\
\hline Unknown & $799(2.1 \%)$ & $280(1.9 \%)$ & $519(2.2 \%)$ & 0.015 \\
\hline Other & $1278(3.3 \%)$ & $544(3.6 \%)$ & $734(3.1 \%)$ & 0.012 \\
\hline \multicolumn{5}{|l|}{ Clinical characteristics } \\
\hline Charlson Comorbidity Score, median (IQR) & $3(1-5)$ & $3(2-5)$ & $3(1-4)$ & $<0.001$ \\
\hline Body mass index, median (IQR) & $28.8(24-35.3)$ & $28.9(24-35.6)$ & $28.7(24.1-35)$ & 0.111 \\
\hline \multicolumn{5}{|l|}{ Comorbidities, n (\%) } \\
\hline History of cancer & $8593(22.3 \%)$ & $2669(17.6 \%)$ & $5924(25.2 \%)$ & $<0.001$ \\
\hline History of COPD & $9540(24.7 \%)$ & $3006(19.9 \%)$ & $6534(27.8 \%)$ & $<0.001$ \\
\hline History of CHF & $10001(25.9 \%)$ & $2944(19.5 \%)$ & $7057(30.1 \%)$ & $<0.001$ \\
\hline History of Ml & $5813(15.1 \%)$ & $1786(11.8 \%)$ & $4027(17.2 \%)$ & $<0.001$ \\
\hline History of arthritis & $2227(5.8 \%)$ & $812(5.4 \%)$ & $1415(6 \%)$ & 0.006 \\
\hline History of DVT & $5244(13.6 \%)$ & $1923(12.7 \%)$ & $3321(14.2 \%)$ & $<0.001$ \\
\hline History of PE & $2704(7.0 \%)$ & $940(6.2 \%)$ & $1764(7.5 \%)$ & $<0.001$ \\
\hline History of lung disease & $15600(40.4 \%)$ & $5048(33.4 \%)$ & $10552(45 \%)$ & $<0.001$ \\
\hline History of severe illness & $9962(25.8 \%)$ & $1398(9.2 \%)$ & $8564(36.5 \%)$ & $<0.001$ \\
\hline History of pneumonia & $10778(27.9 \%)$ & $3274(21.6 \%)$ & $7504(32 \%)$ & $<0.001$ \\
\hline History of sepsis & $16430(42.6 \%)$ & $7263(48 \%)$ & $9167(39.1 \%)$ & $<0.001$ \\
\hline History of CVA/TIA & $6271(16.2 \%)$ & $2051(13.6 \%)$ & $4220(18 \%)$ & $<0.001$ \\
\hline History of osteomyelitis & $5329(13.8 \%)$ & $3753(24.8 \%)$ & $1576(6.7 \%)$ & $<0.001$ \\
\hline History of cellulitis & $7124(18.5 \%)$ & $4467(29.5 \%)$ & $2657(11.3 \%)$ & $<0.001$ \\
\hline Cerebrovascular disease & $5822(15.1 \%)$ & $1926(12.7 \%)$ & $3896(16.6 \%)$ & $<0.001$ \\
\hline Dementia & $2945(7.6 \%)$ & $1109(7.3 \%)$ & $1836(7.8 \%)$ & 0.074 \\
\hline Diabetes-complicated & $8427(21.8 \%)$ & $3777(25 \%)$ & $4650(19.8 \%)$ & $<0.001$ \\
\hline Diabetes_uncomplicated & $7137(18.5 \%)$ & $2641(17.5 \%)$ & $4496(19.2 \%)$ & $<0.001$ \\
\hline Hypertension & $25931(67.2 \%)$ & $10025(66.3 \%)$ & $15906(67.8 \%)$ & 0.002 \\
\hline Mild liver disease & $2473(6.4 \%)$ & $935(6.2 \%)$ & $1538(6.6 \%)$ & 0.143 \\
\hline Severe CKD & $13398(34.7 \%)$ & $3935(26 \%)$ & $9463(40.3 \%)$ & $<0.001$ \\
\hline Peripheral vascular disease & $6079(15.8 \%)$ & $2669(17.6 \%)$ & $3410(14.5 \%)$ & $<0.001$ \\
\hline Active cancer & $2568(6.7 \%)$ & $513(3.4 \%)$ & $2055(8.8 \%)$ & $<0.001$ \\
\hline \multicolumn{5}{|l|}{ Laboratory values, median (IQR) } \\
\hline Haemoglobin & $10.3(8.8-11.8)$ & $10.1(8.6-11.7)$ & $10.6(9.2-12)$ & $<0.001$ \\
\hline White blood cell count & $9(6.6-12.3)$ & $9.5(6.8-13.3)$ & $8.3(6.4-10.9)$ & 0.377 \\
\hline Platelets ( $\times 10^{9}$ per litre) & $237(170-322)$ & $221(156-302)$ & $263(194-352)$ & $<0.001$ \\
\hline eGFR & $61(54-93)$ & $60(41-87)$ & $77(60-101)$ & 0.006 \\
\hline International normalised ratio & $1.14(1.02-1.31)$ & $1.14(1.03-1.33)$ & $1.14(1.02-1.3)$ & 0.702 \\
\hline \multicolumn{5}{|l|}{ Device characteristics } \\
\hline PICC days, median (IQR) & $17(7-30)$ & $10(5-28)$ & $30(15-35)$ & $<0.001$ \\
\hline Gauge (Fr), median (IQR) & $5(4-5)$ & $5(5-5)$ & $4(4-4)$ & $<0.001$ \\
\hline \multicolumn{5}{|l|}{ Number of lumens, $n(\%)$} \\
\hline Single & $19322(50.1 \%)$ & $15128(100 \%)$ & $4194(17.9 \%)$ & $<0.001$ \\
\hline Double & $15785(40.9 \%)$ & & $15785(67.3 \%)$ & \\
\hline Triple & $3483(9.0 \%)$ & & $3483(14.8 \%)$ & \\
\hline Quadruple & $2(0.0 \%)$ & & $2(0.0 \%)$ & \\
\hline Dwell time $\leq 5$ days, $n(\%)$ & $6860(17.8 \%)$ & & $6860(29.2 \%)$ & \\
\hline
\end{tabular}


Table 1 Continued

\begin{tabular}{|c|c|c|c|c|}
\hline & $\begin{array}{l}\text { Total } \\
(\mathrm{n}=38592)\end{array}$ & $\begin{array}{l}\text { Appropriate placement } \\
(\mathrm{n}=15128)\end{array}$ & $\begin{array}{l}\text { Inappropriate placement } \\
(n=23464)\end{array}$ & $P$ value \\
\hline PICC in patients with CKD, $\mathrm{n}(\%)$ & $6084(15.8 \%)$ & & $6084(25.9 \%)$ & \\
\hline \multicolumn{5}{|l|}{ Indications for PICCS, n (\%) } \\
\hline Antibiotics & $20048(51.9 \%)$ & $12342(81.6 \%)$ & $7706(32.8 \%)$ & $<0.001$ \\
\hline Blood transfusion or blood products & $179(0.5 \%)$ & $14(0.1 \%)$ & $165(0.7 \%)$ & $<0.001$ \\
\hline Chemotherapy & $1270(3.3 \%)$ & $129(0.9 \%)$ & $1141(4.9 \%)$ & $<0.001$ \\
\hline Difficult access/blood draws & $7844(20.3 \%)$ & $1292(8.5 \%)$ & $6552(27.9 \%)$ & $<0.001$ \\
\hline Medications requiring central access & $4533(11.7 \%)$ & $731(4.8 \%)$ & $3802(16.2 \%)$ & $<0.001$ \\
\hline Multiple incompatible fluids & $803(2.1 \%)$ & $26(0.2 \%)$ & $777(3.3 \%)$ & $<0.001$ \\
\hline Parenteral nutrition & $2691(7 \%)$ & $190(1.3 \%)$ & $2501(10.7 \%)$ & $<0.001$ \\
\hline $\begin{array}{l}\text { Medication requiring central access per hospital } \\
\text { policy }\end{array}$ & $98(0.3 \%)$ & $9(0.1 \%)$ & $89(0.4 \%)$ & $<0.001$ \\
\hline Unknown & $3598(9.3 \%)$ & $884(5.8 \%)$ & $2714(11.6 \%)$ & $<0.001$ \\
\hline ICU setting, N (\%) & $10953(28.4 \%)$ & $852(5.6 \%)$ & $10101(43 \%)$ & $<0.002$ \\
\hline \multicolumn{5}{|l|}{ Operator/Inserter, N (\%) } \\
\hline Vascular access team & $26644(69.0 \%)$ & $10666(70.5 \%)$ & $15978(68.1 \%)$ & $<0.001$ \\
\hline Interventional Radiology & $7171(18.6 \%)$ & $2679(17.7 \%)$ & $4492(19.1 \%)$ & $<0.001$ \\
\hline \multicolumn{5}{|l|}{ Site-level characteristics } \\
\hline Bed size, median (IQR) & $380(273-584)$ & $391(283-632)$ & $379(250-537)$ & $<0.001$ \\
\hline Total number of discharges, median (IQR) & $19591(12453-29763)$ & $19591(13245-29763)$ & 19307 (10873-29763) & $<0.001$ \\
\hline Teaching hospital, \% & $37367(96.8 \%)$ & $14471(95.7 \%)$ & $22896(97.6 \%)$ & $<0.001$ \\
\hline Non-profit, \% & $31401(81.4 \%)$ & $12479(82.5 \%)$ & $18922(80.6 \%)$ & $<0.001$ \\
\hline For-profit, \% & $2381(6.2 \%)$ & $1069(7.1 \%)$ & $1312(5.6 \%)$ & $<0.001$ \\
\hline Government, \% & $3137(8.1 \%)$ & $796(5.3 \%)$ & $2341(10.0 \%)$ & $<0.001$ \\
\hline
\end{tabular}

BMI, body mass index; CHF, congestive heart failure; CKD, chronic kidney disease; CLABSI, central line-associated bloodstream infection; COPD, Chronic Obstructive Pulmonary Disease; CVA/TIA, cerebrovascular accident/transient ischaemic attack; CVC, central venous catheter; DVT, deep vein thrombosis; eGFR, estimated glomerular filtration rate; IBS, irritable bowel syndrome; ICU, intensive care unit; MI, Myocardial Infarction; PE, pulmonary embolism; PICC, peripherally inserted central catheter.

of absolute decrease 3.6\%-27.3\% across hospitals). For PICC use in CKD, appropriateness improved from $17.3 \%$ preintervention to $13.7 \%$ postintervention (absolute reduction $=3.6 \%$, range of absolute improvement $0.0 \%-29.0 \%$ across hospitals, $\mathrm{p}<0.001)$.

During the study, PICC-related complications decreased from $14.7 \%$ to $10.7 \%$ ( $p=0.001,0.0 \%-$ $26.6 \%$ across hospitals postintervention). Across hospitals, reductions in complication events preintervention versus postintervention ranged from $-15.4 \%$ to $+9.2 \%$ (figure 2 ). Catheter occlusion improved the most, decreasing from $10.6 \%$ to $7.4 \%$ ( $<<0.001$,

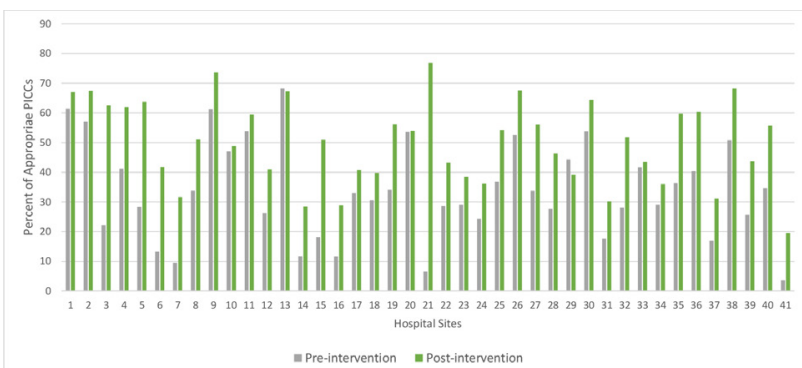

Figure 1 Bar graph illustrating per cent of PICCs meeting all 3 Appropriateness Criteria in 41 Michigan Hospitals (preintervention vs postintervention). PICC, peripherally inserted central catheter.
$0.0 \%$ to $25.0 \%$ across hospitals). Similarly, VTE decreased from $3.3 \%$ to $2.5 \%$ (p< $<0.001,0.0 \%$ to $8.7 \%$ across hospitals). Specifically, upper-extremity DVT decreased from $2.0 \%$ to $1.4 \%(\mathrm{p}<0.001,-1.3 \%$ to $3.9 \%$ across hospitals). CLABSI decreased from $1.8 \%$ to $1.4 \%$ ( $\mathrm{p}=0.015,0.0 \%$ to $4.1 \%$ across hospitals).

\section{Association between intervention and outcomes}

Using CUSUM, change points were identified at February 14, 2017 (95\% CI (14 January 2017 to 17 March 2017)) for appropriateness and 15 May 2017 (95\% CI (3 January 2017 to 28 March 2017))

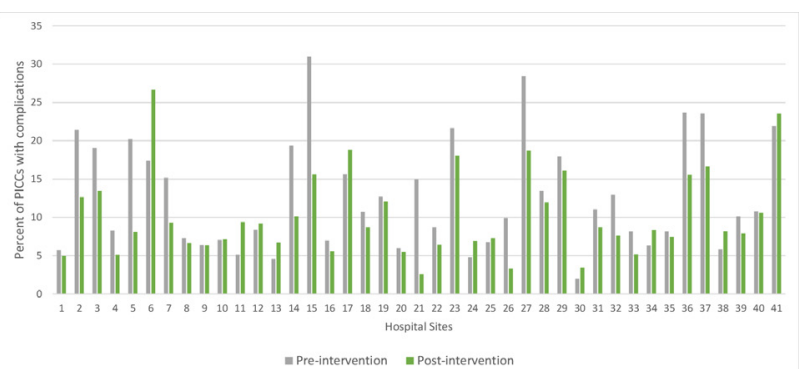

Figure 2 Bar graph illustrating per cent of PICCs with complications in 41 Michigan Hospitals (preintervention vs postintervention). PICC, peripherally inserted central catheter. 
Table 2 Association between catheter appropriateness and risk of complications

\begin{tabular}{|c|c|c|c|c|c|c|}
\hline \multirow[b]{2}{*}{ Occlusion } & \multicolumn{2}{|c|}{$\begin{array}{l}\text { Appropriate PICC placement } \\
(\mathrm{n}=15128), \text { no. }(\%)\end{array}$} & \multicolumn{2}{|c|}{$\begin{array}{l}\text { Inappropriate PICC placement } \\
(\mathrm{n}=23464), \text { no. }(\%)\end{array}$} & \multirow{2}{*}{$\frac{\text { OR }(95 \% \mathrm{Cl})}{0.25(0.21 \text { to } 0.29)}$} & \multirow{2}{*}{$\begin{array}{l}\text { P value } \\
<0.001\end{array}$} \\
\hline & 572 & $3.78 \%$ & 2998 & $12.78 \%$ & & \\
\hline CLABSI & 136 & $0.90 \%$ & 490 & $2.09 \%$ & 0.61 (0.46 to 0.81$)$ & 0.001 \\
\hline VTE & 214 & $1.41 \%$ & 925 & $3.94 \%$ & 0.40 (0.33 to 0.47$)$ & $<0.001$ \\
\hline All complications & 884 & $5.84 \%$ & 4130 & $17.60 \%$ & $0.29(0.25$ to 0.34$)$ & $<0.001$ \\
\hline
\end{tabular}

Mixed-effects logistic model including hospital random effects and year fixed effects. All models control for patient characteristics (sex, age, Charlson Comorbidity Score, BMI, history of cancer, indication of current CVC at time of PICC placement, line duration).

BMI, body mass index; CLABSI, central line-associated bloodstream infection; CVC, central venous catheter; PICC, peripherally inserted central catheter; VTE, venous thromboembolism.

for PICC-associated complications. For both change points, the bootstrapped estimates were smaller than the original CUSUM estimate $>99 \%$ of the time, providing strong evidence that rates of appropriateness and complications changed during this period (online supplemental figure).

\section{Association between appropriateness and complications}

Following adjustment, compared with patients with inappropriate PICC placement, appropriate PICC use was associated with a significantly lower odds of major complications (OR $0.29,95 \%$ CI 0.25 to 0.34 ). Reductions were observed for all major complications, including catheter occlusion (OR $0.25,95 \%$ CI 0.21 to 0.29), CLABSI (OR 0.61, 95\% CI 0.46 to 0.81), VTE (OR $0.40,95 \%$ CI 0.33 to 0.47 ) and upper-extremity DVT (OR $0.40,95 \%$ CI 0.32 to 0.49 , all $\mathrm{p}<0.001$ ) (table 2). Greater PICC appropriateness was associated with fewer complications (OR $0.72,95 \%$ CI 0.60 to 0.86 ; Pearson correlation $=-0.26, \mathrm{p}<0.001$ for both). In a Poisson model examining association between appropriateness and complications, patients with appropriate PICC placement experienced a lower rate of major complications than those with inappropriate PICCs (IRR 0.987, 95\% CI 0.98 to $0.99, \mathrm{p}<0.001$ ).

\section{DISCUSSION}

In this multicentre quasiexperimental interventional study, MAGIC implementation in 52 Michigan hospitals was associated with improved PICC appropriateness. Moreover, compared with inappropriate PICC use, appropriate PICC use was associated with a reduction in major complications (OR $0.29,95 \%$ CI 0.25 to 0.34 ; IRR $0.987,95 \%$ CI 0.98 to $0.99, \mathrm{p}<0.001$ ). Given the large number of included hospitals and reduction in the incidence of costly, morbid and potentially lethal complications, broader use of MAGIC in hospitals appears warranted.

Appropriateness criteria have been in use since the 1970s and have traditionally focused on providing guidance on best practices when evidence is unclear or uncertain. These criteria have also been used by policymakers to assess quality of care, inform financial reimbursement and payment and assess the value of services provided to patients. Few appropriatenessbased criteria, however, have moved from a theoretical realm (ie, what should be done) to daily clinical practice (ie, what is done). A notable exception is the American College of Radiology Appropriateness Criteria guidance, which has translated recommendations into computerised decision support at the point-of-care using a designated platform (ACR Select). ${ }^{19}$ At inception, MAGIC was created using a similar approach: recommendations such as limiting the number of lumens or not placing PICCs in patients with CKD are meaningful and accessible to ordering providers. Importantly, while ACR and other appropriateness criteria have focused primarily on reducing healthcare costs, MAGIC also aimed at preventing complications. The recommendation to avoid short-term PICC use is a prime example as alternative, lower risk devices, may be used for this period.

While limited, data showing that MAGIC can be used to assess appropriateness and improve practice are promising and growing. In a study by Swaminathan et al, MAGIC implementation using a combination of education and feedback at a single site reduced PICC complications compared with control sites. ${ }^{10}$ In a study by investigators in Ontario, applying MAGIC to measure appropriateness of catheter use in a provincial database was found to be feasible with a substantial proportion of PICCs deemed either uncertain or inappropriate-suggesting room for improving quality of care. ${ }^{20}$ Similarly, a national study of Medicare recipients found that the publication of MAGIC was associated with reductions in overall PICC use in the US. ${ }^{21}$ The present study advances these findings by showing a significant association between PICC appropriateness and complications across multiple hospitals. In addition, the structured MAGIC implementation yielded significant increase in appropriateness of PICC use and a contemporaneous decrease in complications. ${ }^{1022}$ Moreover, using our current data, a 'back of the envelope' estimate on potential financial impact suggests substantial savings may be realised as a result of MAGIC. Assuming costs of $\$ 145$ for catheter occlusion, $\$ 15000$ per episode of VTE and $\$ 12000$ for CLABSI, we estimated savings of $\$ 2.9$ million from prevention of complications and 
an estimated \$231675 savings on average for an individual hospital. ${ }^{81323}$ Notably, the degree of improvement at individual hospitals was variable with some experiencing dramatic change and others, less so. To gain a greater understanding of which aspects of implementation (eg, the quality of the delivery of the intervention at each site, use of ordersets versus clinical champions and programme differentiation) contributed to our findings, a combination of site visits and qualitative work is ongoing. We anticipate that these qualitative aspects will lend greater insight into what works, what doesn't and why for hospitals interested in implementing MAGIC.

Our study has limitations. First, given the quality improvement nature of the work, we used an observational study design without a control group. Thus, secular trends or unmeasured confounding may influence our findings. However, to counteract this aspect, we used rigorous analysis including assessment of temporarily of change in relation to introduction of the intervention for confirmation. Second, although models were fully adjusted and we used multiple analyses that included hospital and patient characteristics, our data can only show association-not causation between PICC appropriateness and major complications. Third, patients were included from select hospitals in Michigan that agreed to participate in our initiative and received financial compensation for the same. Given the size of our intervention and inclusion of multiple hospitals (representing close to $80 \%$ of all hospital beds in Michigan), we have no reason to believe that this would introduce systematic bias in patient outcomes. However, it is possible that hospital engagement and pay for performance amplified the impact of our intervention. As our interventions targeted process issues such as number of lumens and dwell time, payments were relatively small and the included hospitals represent the majority of all acute care settings in the State of Michigan, we believe our findings are generalisable. Finally, we do not know which of our intervention components was the 'active ingredient(s)' in achieving our results; however, qualitative work to better understand this aspect is ongoing.

Our study also has important strengths. To our knowledge, this is the first study showing that implementing MAGIC can lead to both improved catheter appropriateness and patient outcomes. Our findings also suggest that reduction in PICC complications across sites may have substantial economic implications for hospitals, with estimated savings from reduced complications potentially summing to over US $\$ 8 \mathrm{M}^{823-25}$ In an era of publicly reported measures and resource limitations, the business case to turn to MAGIC as a platform to improving safety and reducing costs in vascular access is therefore compelling. Second, the implementation toolkit used to deploy MAGIC is online and available to the public; it can thus be used by other hospitals, creating a novel and timely resource to improve PICC safety beyond this work. ${ }^{15}$ Third, because implementation was associated with reduction in costly complications such as VTE and CLABSI, our findings have substantial quality and safety implications for hospitals struggling with these two events. Finally, we used robust methods to validate our findings including those focused on temporality of outcomes related to the intervention and mixed models taking into account clinically relevant confounders. This rigour gives us confidence that our findings are replicable outside our collaborative, especially if the impetus to improve vascular device outcomes in a given hospital is substantial.

In conclusion, our intervention based on MAGIC led to improved PICC appropriateness and reduced patient harm across thousands of patients. Wider use and adoption of MAGIC as a resource to measure, evaluate and improve PICC safety appears warranted.

\section{Twitter Vineet Chopra @vineet_chopra}

Contributors All authors contributed to the study design, data analysis and interpretation and manuscript drafting and revision.

Funding Blue Cross/Blue Shield of Michigan and Blue Care Network supported data collection at each participating site and funded the data coordinating centre but had no role in study concept, interpretation of findings or in the preparation, final approval or decision to submit the manuscript.

Patient consent for publication Not required.

Ethics approval As the purpose of this state-wide collaborative is to measure and improve the quality of existing care practices, this study was assigned a 'not regulated' status.

Provenance and peer review Not commissioned; externally peer reviewed.

Data availability statement Given the quality improvement nature, data collected for the study will not be made available to others. However, our online toolkit is available to the public at https://www.improvepicc.com/implementation.html. More details can be found at https://mi-hms.org/quality-initiatives/ peripherally-inserted-central-catheter-picc-use-initiative.

Supplemental material This content has been supplied by the author(s). It has not been vetted by BMJ Publishing Group Limited (BMJ) and may not have been peer-reviewed. Any opinions or recommendations discussed are solely those of the author(s) and are not endorsed by BMJ. BMJ disclaims all liability and responsibility arising from any reliance placed on the content. Where the content includes any translated material, BMJ does not warrant the accuracy and reliability of the translations (including but not limited to local regulations, clinical guidelines, terminology, drug names and drug dosages), and is not responsible for any error and/or omissions arising from translation and adaptation or otherwise.

Open access This is an open access article distributed in accordance with the Creative Commons Attribution Non Commercial (CC BY-NC 4.0) license, which permits others to distribute, remix, adapt, build upon this work noncommercially, and license their derivative works on different terms, provided the original work is properly cited, appropriate credit is given, any changes made indicated, and the use is noncommercial. See: http://creativecommons.org/licenses/by-nc/4. $0 /$.

ORCID iD

Vineet Chopra http://orcid.org/0000-0001-8670-9376 


\section{REFERENCES}

1 Climo M, Diekema D, Warren DK, et al. Prevalence of the use of central venous access devices within and outside of the intensive care unit: results of a survey among hospitals in the prevention epicenter program of the centers for disease control and prevention. Infect Control Hosp Epidemiol $2003 ; 24: 942-5$.

2 Meyer BM. Developing an alternative workflow model for peripherally inserted central catheter placement. J Infus Nurs 2012;35:34-42.

3 Chopra V, Anand S, Hickner A, et al. Risk of venous thromboembolism associated with peripherally inserted central catheters: a systematic review and meta-analysis. Lancet 2013;382:311-25.

4 Ajenjo MC, Morley JC, Russo AJ, et al. Peripherally inserted central venous catheter-associated bloodstream infections in hospitalized adult patients. Infect Control Hosp Epidemiol 2011;32:125-30.

5 Chopra V, Flanders SA, Saint S. The problem with peripherally inserted central catheters. JAMA 2012;308:1527-8.

6 Greene MT, Flanders SA, Woller SC, et al. The association between PICC use and venous thromboembolism in upper and lower extremities. Am J Med 2015;128:986-93.

7 Chopra V, Smith S, Swaminathan L, et al. Variations in peripherally inserted central catheter use and outcomes in Michigan hospitals. JAMA Intern Med 2016;176:548-51.

8 Smith SN, Moureau N, Vaughn VM, et al. Patterns and predictors of peripherally inserted central catheter occlusion: the 3P-O study. J Vasc Interv Radiol 2017;28:749-56.

9 Chopra V, Flanders SA, Saint S, et al. The Michigan appropriateness guide for intravenous catheters (magic): results from a Multispecialty panel using the RAND/UCLA appropriateness method. Ann Intern Med 2015;163:S1-40.

10 Swaminathan L, Flanders S, Rogers M, et al. Improving PICC use and outcomes in hospitalised patients: an interrupted time series study using magic criteria. BMJ Qual Saf 2018;27:271-8.

11 Michigan Hospital Medicine Safety Consortium. Peripherally inserted central catheter initiative, 2020. Available: https:// mi-hms.org/quality-initiatives/peripherally-inserted-centralcatheter-picc-use-initiative

12 Chopra V, Kaatz S, Conlon A, et al. The Michigan risk score to predict peripherally inserted central catheter-associated thrombosis. J Thromb Haemost 2017;15:1951-62.

13 Herc E, Patel P, Washer LL, et al. A model to predict CentralLine-Associated bloodstream infection among patients with peripherally inserted central catheters: the MPC score. Infect Control Hosp Epidemiol 2017;38:1155-66.
14 Landes SJ, McBain SA, Curran GM. An introduction to effectiveness-implementation hybrid designs. Psychiatry Res 2019;280:112513.

15 Peripherally inserted central catheter (PICC) quality improvement toolkit, 2021. Michigan Hospital medicine safety Consortium. Available: https://www.improvepicc.com/ implementation.html [Accessed 25 Feb 2021].

16 Bloodstream infection event (central line-associated BloodstreamInfection and non-central line-associated bloodstream infection). CDC bloodstream infection/device associated infection module, 2020. Available: https://www.cdc. gov/nhsn/pdfs/pscmanual/4psc_clabscurrent.pdf

17 Taylor WA. Change-Point analysis: a powerful new tool for detecting changes, 2010. Available: https://variation.com/wpcontent/uploads/change-point-analyzer/change-point-analysisa-powerful-new-tool-for-detecting-changes.pdf

18 Aylin P, Best N, Bottle A, et al. Following Shipman: a pilot system for monitoring mortality rates in primary care. Lancet 2003;362:485-91.

19 American College of Radiology ACR Appropriateness Criteria ${ }^{\circledR}$. Radiologic management of central venous access, 2020. Available: https://acsearch.acr.org/docs/3094281/ Narrative/

20 Verma AA, Kumachev A, Shah S, et al. Appropriateness of peripherally inserted central catheter use among general medical inpatients: an observational study using routinely collected data. BMJ Qual Saf 2020;29:905-11.

21 Lindquester WS, Dhangana R, Warhadpande S, et al. Effects of the magic guidelines on PICC placement volume: advanced practice provider and physician trends amongst Medicare beneficiaries from 2010-2018. AJR Am J Roentgenol 2020. doi:10.2214/AJR.20.23704. [Epub ahead of print: 26 Aug 2020].

22 Rogers M, Flanders S, McLaughlin E. Applying magic to improve PICC appropriateness in 42 Michigan hospitals. Abstract published at hospital medicine 2019, March 2427, National harbor, MD. Abstract 10. Available: https:// shmabstracts.org/abstract/applying-magic-to-improve-piccappropriateness-in-42-michigan-hospitals/

23 Evans RS, Sharp JH, Linford LH, et al. Reduction of peripherally inserted central catheter-associated DVT. Chest 2013;143:627-33.

24 Warren DK, Quadir WW, Hollenbeak CS, et al. Attributable cost of catheter-associated bloodstream infections among intensive care patients in a nonteaching Hospital. Crit Care Med 2006;34:2084-9.

25 Al-Rawajfah OM, Hewitt JB, Stetzer F, et al. Length of stay and charges associated with health care-acquired bloodstream infections. Am J Infect Control 2012;40:227-32. 